\title{
COMMONWEALTH OCEANOGRAPHIC CONFERENCE
}

$\mathrm{T}$ HE idea of a Commonwealth Oceanographic Conference was first put forward at a meeting of the National Oceanographic Council in January 1953. It arose from arguments that the change of emphasis in oceanography, from exploration and survey to research directed towards the precise understanding of the basic physical and biological processes, makes it necessary to devote more effort to theoretical and experimental work. For example, biologists as well as physicists want to know more about the changes in the surface currents and the speeds and variations of the slow but powerful deep-water movements, and it is no longer possible or reasonable to attempt to keep a watch on them all with a network of oceanographic observations like that used in meteorology. The only practical thing is for oceanographers to learn how the water movements are governed by atmospheric pressure, wind and climate so that they can use the meteorological data, supplemented every now and then by their own upper-and lower-water observations.

It would, no doubt, be wrong to suggest that oceanographers took up the subject because they found mathematical and physical sciences too difficult and unattractive; but they have been rather slow in applying the precise techniques of these sciences to marine research. There is more than sufficient interest and profit in the study of the marine animals and plants to keep the marine laboratory busy; but there would be just as much interest and profit in the study of the magnificent interplay between sun, water, air and earth if only we knew rather more about it to begin with. To increase our knowledge the subject must be made attractive to men who do not mind facing up to the difficulties of fluid mechanics. The experienced investigators who have done so much exploration and survey and built up a realistic basic picture can scarcely be expected to turn their hands to the fresh intricacies of such new tasks.

The progress in any science can probably be measured by the interest which the universities take in it; and in oceanography their interest, with one or two notable exceptions, is limited to the biology of the coast and shallow seas. This is understandable, since the problems are interesting and important, and there is much that can be fitted conveniently into university life. As soon as the collection of data becomes too expensive for university departments, and the problems too difficult to afford reasonable expectation that a student can make sufficient progress in two years to sit for a higher degree, the work has to be left to State-aided marine laboratories, and men have to be paid to do it. Even then it is rather difficult to attract first-class men, and a fair number are needed, since nothing less than a team with similar interests is likely to make much headway with a really backward subject.

Most countries of the British Commonwealth engage in oceanography on a considerable scale, dividing their resources between long-term research and the application of existing knowledge to their immediate problems. They all want to increase their activity; but the difficulties of attracting sufficient men with special qualifications and experi- ence, the rising cost of designing and constructing the necessary apparatus and of building, operating and maintaining ocean-going research ships will, sooner or later, make some sharing of the basic studies essential.

The purpose of the Commonwealth Oceanographic Conference held during October 18-22 at the National Institute of Oceanography at Wormley, which was attended by delegates and observers from all Commonwealth countries as well as representatives of authorities interested in marine research in the United Kingdom, was to review the progress of oceanographic research in the Commonwealth, to discuss what measures might be taken to promote its extension, and to further the co-operative use of the available effort and facilities.

The Conference considered the applications of oceanographic research to defence, coastal engineering, shipping, meteorology and fisheries, and concluded that more use could be made of oceanographic research. It was also generally agreed that the investigation of local problems would be furthered by a better understanding of the basic physical and biological processes. It was agreed that the processes most deserving attention are those involved in the interchange of energy between the atmosphere and oceans, response of the sea surface to winds and pressure changes, general circulation of the oceans, distribution of marine organisms and organic production in the oceans. It was recognized that there are other important aspects, but progress in them is more satisfactory, and the immediate need is to direct attention to subjects which require much closer study before our understanding of the underlying principles of oceanography can be sufficient to allow real progress.

The Conference agreed on $a$ co-operative scheme for lending equipment that is expensive, difficult to obtain, and probably only used occasionally, and arranged for the scheme to be started by the National Institute of Oceanography, which had announced its intention to build up a reserve of equipment.

Arrangements for disseminating information similar to those used by the Fuel Research Organization and the Aeronautical Research Council in Commonwealth countries were also agreed. The subject was divided into ten branches, for each of which a chief coordinator, located somewhere in the Commonwealth, was proposed : a national representative would pass reports of work done in his country in each of these branches to the appropriate chief co-ordinators, who would summarize and edit information and distribute it annually. It may be doubted whether such a scheme will succeed, but oceanography is a science in which publication, with reasonable confirmation, tends to lag well behind the formation of ideas, and though the tasks of the national representatives and the co-ordinators will be heavy, men with great enthusiasm may produce very useful results. Some benefit will be obtained from the mere fact that the national representative has to judge what contribution his country is making to the systematic development of the subject rather than to knowledge of local conditions. 
The need for training more oceanographers was emphasized, and it was decided that the universities should be asked to help by teaching oceanography and doing all they can to encourage postgraduate research in marine physics as well as marine biology.

The Conference endorsed the programme of the National Institute of Oceanography, and considered that its attempt to concentrate on the basic problems, which will benefit the Commonwealth countries by helping them to solve their local problems, should be supported as fully as possible.

The First Lord of the Admiralty, the Right Hon. J. P. L. Thomas, and the Civil Lord, Mr. Simon Wingfield Digby, chairman of the National Oceanographic Council, did much to encourage the work of the Conference. They were hosts at a reception to all members after the first day's session and at $a_{0}$ dinner, at which the First Lord presided, given in honour of the Commonwealth representatives, at the close of the meetings.

\section{NEW FORMS OF THERMIONIC CATHODE}

A

COLLOQUIUM on new forms of thermionic cathode, sponsored by the Institute of Physics and the Physical Society, was held on October 21 at Hirst Hall on the estate at Wembley of the General Electric Company, Ltd., An introductory survey was given by D. A. Wright (G.E.C., Wembley), who pointed out that, for continuous operation for many thousands of hours, none of the established cathodes (Nos. 1, 3 and 9 in Table 1) can be relied upon to give more than 1-2 amp. $/ \mathrm{cm}^{2}$. The oxide cathode will give some tens of amp. $/ \mathrm{cm}^{2}$ in short pulses, but is limited for continuous high current by its sensitiveness to imperfect vacuum, by the dielectric properties of the coating and by evaporation and electrolysis of coating material. Thus, to improve the performance, a cathode with metallic properties is desirable, with a low rate of loss of emissive material. The lowest-temperature emitter obtainable without a dielectric coating appears to be that which maintains a monatomic layer of barium on a metal surface, possibly with some oxygen present. The work function of such a cathode is $1 \cdot 6-2 \cdot 0 \mathrm{eV}$., so that it must be operated at $950^{\circ} \mathrm{C}$. or more. At these temperatures, surface barium is rapidly lost by evaporation, and must be replaced from a reservoir in the cathode. The next four papers at the colloquium described cathodes of this type.

Dr. A. Venema (Philips, Eindhoven) described the three forms of Philips dispenser cathode. In the original $L$ cathode (No. 5 in Table 1 ) the reservoir is of barium-strontium carbonate, which decomposes to oxide during pumping and is placed beneath a plug of porous tungsten. The work of Rittner has clarified the mechanism of these cathodes, indicating that barium is formed following reduction of the oxide by the tungsten, and diffuses through the pores as vapour by Knudsen flow. A complete covering of barium on tungsten is maintained by diffusion over the outer surface of the tungsten particles. The life, as shown in the table, exceeds eight thousand hours at a brightness temperature of $950^{\circ} \mathrm{C}$., at which the saturated emission is $1.3 \mathrm{amp} . / \mathrm{cm} .{ }^{2}$. The life is determined by evaporation, and decreases by a factor of $2 \frac{1}{2}$ per $50 \mathrm{deg}$. C. rise of temperature. The impregnated cathode has similar properties, and is formed by heating a porous tungsten plug in contact with barium aluminate at $1,750^{\circ} \mathrm{C}$. in vacuum. The aluminate penetrates the pores, and in operation is reduced by the tungsten. A third type of cathode is being developed, in which tungsten powder and barium aluminate are mixed in powder form, pressed and sintered, again at $1,700-1,800^{\circ} \mathrm{C}$.

In discussing the chemical reactions which can be utilized to supply barium to a tungsten surface, Dr. H. Huber (C.S.F., Paris) said that the compounds barium aluminate, silicate, titanate, thorate and tungstate have been considered. The work of Eisenstein, John and Affleck has shown what reducing agents are appropriate for each compound, and Dr. Huber described the results of his study of the emission of cathodes formed by mixing the powdered oxide, tungsten and a suitable reducing agent, pressing and heating at $1,300^{\circ} \mathrm{C}$. The preferred cathode is ' 103 ' (No. 6 in Table 1), containing five molecular parts of barium tungstate $\left(\mathrm{Ba}_{3} \mathrm{WO}_{6}\right)$, fifteen molecular parts of aluminium powder and eighty of tungsten powder, though similar results are obtained if the aluminium is replaced by tungsten carbide, and molybdenum can replace the tungsten powder. Presintering at $1,500^{\circ} \mathrm{C}$. is found to be necessary to give long life.

It is not possible to form a cathode by mixing barium/strontium carbonate with tungsten, as there is a reaction which prevents subsequent reduction of the oxide to free barium. The carbonate can, however, be mixed with a more inert metal containing a little reducing agent. Dr. J. M. Dodds (Metropolitan-

Table 1

\begin{tabular}{|c|c|c|c|c|c|c|}
\hline Type & $\begin{array}{l}\text { Operating } \\
\text { temperature }\end{array}$ & $\begin{array}{l}\text { Radiated power } \\
\text { (watts } / \mathrm{cm}^{2} \text { ) }\end{array}$ & $\begin{array}{l}\text { Maximum usable } \\
\text { d.c. emission } \\
\left.\text { (amp./cm. }{ }^{2}\right)\end{array}$ & Life† (hr.) & $\begin{array}{l}\text { Work function } \\
(\mathrm{eV} .)\end{array}$ & $\begin{array}{c}\text { Richardson } \\
\boldsymbol{A} \text { value }\end{array}$ \\
\hline $\begin{array}{l}\text { (1) Tungsten } \\
\text { (2) Tantalum } \\
\text { (3) Thoriated tungsten } \\
\text { (4) Lanthanum boride } \\
\text { (5) Philips dispenser } \\
\text { (6) Hubarium-tungsten) } \\
\text { (6) (barium- } \\
\text { (7) Dodds (bartium-nickel) } \\
\text { (8) Beck (barium-nickel) } \\
\text { (9) Oxide cathode }\end{array}$ & $\begin{array}{l}2,600^{\circ} \mathrm{K} . \\
2,400^{\circ} \mathrm{K} . \\
2,000^{\circ} \mathrm{K} . \\
1,680^{\circ} \mathrm{K} . \\
950^{\circ} \mathrm{C.B} . \ddagger \\
1,050^{\circ} \mathrm{C.B} . \\
1,200^{\circ} \mathrm{C} . \mathrm{B} . \\
950^{\circ} \mathrm{C} . \mathrm{B} . \\
1,340^{\circ} \mathrm{K} . \\
1,270^{\circ} \mathrm{K} . \\
1,100^{\circ} \mathrm{K} . \\
1,200^{\circ} \mathrm{K} .\end{array}$ & $\begin{array}{l}80 \\
55 \\
25 \\
40 \\
4^{*} \\
6^{*} \\
8^{*} \\
3 \cdot 3^{*} \\
3 \cdot 7^{*} \\
3 \cdot 0^{*} \\
2 \cdot 8 \\
4 \cdot 2\end{array}$ & $\begin{array}{l}0 \cdot 5 \\
0 \cdot 5 \\
1-3 \\
1 \\
1 \cdot 3 \\
1 \cdot 0 \\
4-5 \\
6 \\
3 \\
1 \cdot 5 \\
0 \cdot 5 \\
1 \cdot 0\end{array}$ & 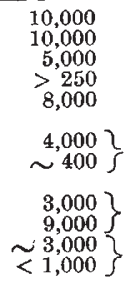 & 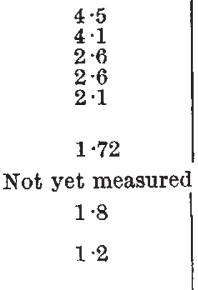 & $\begin{array}{r}60 \\
37 \\
3 \\
25 \\
100 \\
\\
3 \\
\\
20 \\
\sim 1\end{array}$ \\
\hline
\end{tabular}

- These figures assume thermal emissivities for Nos.

(that is, $0 \cdot 2$ ). In practice they are likely to be higher.

+ The figures quoted for life are rough indications only, in all cases.

$\ddagger$ Temperatures in ${ }^{\circ} \mathrm{K}$. are true temperatures. Temperatures in ${ }^{\circ} \mathrm{C} . \mathrm{B}$. are pyrometer brightness temperatures 